\title{
THE RESEARCH ON ELEVATION CHANGE OF ANTARCTIC ICE SHEET BASED ON CRYOSAT-2 ALIMETER DATA
}

\author{
Sun Qinting ${ }^{1}$, Wan Jianhua ${ }^{1}$, Liu Shanwei ${ }^{1}, *$, Li Yinlong ${ }^{1}$ \\ ${ }^{1}$ School of Geosciences, China University of Petroleum(East China),Qingdao,China,s16010068@s.upc.edu.cn
}

Commission III, WG III / 9

KEY WORDS: Antarctic Ice Sheet, Cryosat-2,Satellite Altimetry,DEM, Crossover Adjustment,Kriging Interpolation, Intersection

\begin{abstract}
:
In this paper, the Cryosat-2 altimeter data distributed by the ESA, and these data are processed to extract the information of the elevation change of the Antarctic ice sheet from 2010 to 2017.Firstly, the main pretreatment preprocessing for Cryosat-2 altimetry data is crossover adjustment and elimination of rough difference. Then the grid DEM of the Antarctic ice sheet was constructed by using the kriging interpolation method,and analyzed the spatial characteristic time characteristics of the Antarctic ice sheet. The latitude-weighted elevation can be obtained by using the elevation data of each cycle, and then the general trend of the Antarctic ice sheet elevation variation can be seen roughly.
\end{abstract}

* Corresponding author 


\section{INTRODUCTION}

According to The New York Times, the famous lassen $\mathrm{C}$ ice shelf in Antarctica was rapidly expanding last year. If the Antarctic ice sheet melt would cause global sea levels to rise about $60 \mathrm{~m}$, the coastal cities of the world would be swamped. Research by Pfeffer and Bamber et al. have pointed out that melting ice sheets, including the Antarctic ice sheet and the Greenland ice sheet, contribute significantly to sea level rise(Pfeffer et al. 2008, Bamber et al. 2013) . In recent years, the research on the Antarctic ice sheet has revealed that the Antarctic ice sheet is in a state of accelerated ablation, which will accelerate the sea level rise and have a significant impact on global climate change(Slobbe et al. 2009). Therefore, it is necessary to strengthen the research of the changes of the Antarctic ice sheet.

The polar regions are complex and the means of monitoring the change of the ice sheet are varied, including satellite remote sensing, aerial remote sensing and ground measurement. And aerial remote sensing and ground measurement is timeconsuming, laborious, and coverage of the area is very limited. With the development of remote sensing technology and extensive use in polar regions, it has become the mainstream method to study monitoring and estimating material balance of the ice sheet by means of satellite measurements and gravity satellites(Brenner et al. 2007). Method of Satellite altimetry can get wide range and high precision of the polar ice sheet information.

The comparative analysis of elevation measurements at different periods of the ice sheet can give the elevation change of the Antarctic ice sheet, which can be used to estimate the elevation change trend of the ice sheet. There are five main ways to study the elevation change of ice sheet, after years of research. The first category is the overlapping point method proposed by Slobbe et al. The core idea is to estimate the elevation change of the ice sheet by using the elevation difference in the satellite height footprint. On the one hand it has high precision, on the other hand the number of overlapping points is low, and the utilization of data is low, and it has to use a priori DEM and the complexity of the algorithm(Slobbe et al. 2008). The second class of method is the repeated orbit method, it refers to calculating the elevation change of the ice sheet by using the data of the repeated orbital algebra with the same orbit number. It has higher requirements for the spatial resolution of the a priori DEM.The third category is plane fitting of repeat tracks method, which is able to use the satellite data points effectively, but the mixed data affect the precision(Pritchard et al. 2009). The fourth class is the calculation method based on DEM time series, which construct the DEM of ice sheet by using the altimeter data of the corresponding cycle, and it is easy to implement.The fifth category is the intersection method, the elevation changes during an interval of time can be obtained by comparing the crossover point difference between ascend pass and descend pass. This method can overcome the system error associated with satellite altimetry itself, and it is currently used more and more accurate method.

In contrast to traditional satellite altimetry data, Cryosat-2 satellite altimetry data can provide high spatial resolution and accurate monitoring of the Antarctic ice sheet to obtain the detailed topography and elevation changes of the Antarctic ice sheet. In this paper, the Cryosat- 2 altimeter data distributed by the ESA, and these data are processed to study the monitoring method from 2010 to 2017, and to extract the information of the elevation change of the Antarctic ice sheet.

\section{DATA PROCESSING}

Cryosat-2 satellite was launched on 8th Apr 2016, and the mission is to observe the polar ice caps and sea ice. The repeated cycles were 369 days, and the sub-cycles were 30 days, with 5344 pass measurements per cycle. The satellite altimetry data of Cryosat-2 from 2010 to 2017 which was obtained from the European space agency(ESA).

Since the cycle code of altimetry data is confusing, it is necessary to number the cycle in ascending order, and divided into eight cycles. The Cryosat-2 level2 GDR data has been corrected by waveform re-tracking, altimeter error correction, and slope error correction. However, due to the influence of Earth's rotation, radial orbital errors and systematic errors, and there will be an intersection between the ascending and descending pass. The ice sheet measurement at the intersection is theoretically almost unchanged, namely the crossover point difference should be zero, but the fact that the elevation value at the crossover point shall not be equal, and there is a certain deviation, which will have a large impact on the construction of DEM and monitoring the elevation change of the Antarctic ice sheet. So it is necessary to make the crossover adjustment for cryosat-2 satellite altimetry data.

It is necessary to determine the crossover points at first, in general, there is no observed data at the crossover points.And the difference of crossover points is needed to be inserted by the neighboring points, and then the sea surface height is obtained after correction deviation. The Cryosat- 2 data is divided according to the period, and the ascending and descending pass of each cycle are separated. After the correction deviation, the intersection discontinuity of the data before and after the crossover adjustment is counted, and the results are shown in Table 1. It can be seen that the RMS has significantly decreased after the crossover adjustment.

\begin{tabular}{|l|c|c|}
\hline cycle & $\begin{array}{c}\text { Rms } \\
\text { (before) }\end{array}$ & $\begin{array}{c}\text { Rms } \\
\text { (after) }\end{array}$ \\
\hline 1 & $\mathrm{~cm}$ & $\mathrm{~cm}$ \\
2 & 20.70 & 16.12 \\
3 & 19.94 & 15.12 \\
4 & 20.36 & 16.26 \\
5 & 20.38 & 16.39 \\
6 & 21.49 & 16.18 \\
7 & 20.57 & 16.29 \\
8 & 20.31 & 15.54 \\
\hline
\end{tabular}

Table1.The crossover difference between before and after crossover adjustment

\section{ELEVATION CHANGES OF ANTARCTIC ICE SHEET}

The high spatial resolution and high precision DEM of the Antarctic ice sheet have an important role in understanding the Antarctic ice sheet. The elevation changes of the ice sheet can be monitored by using the constructed DEM data. In the construction of Antarctic ice sheet DEM, different interpolation methods have a greater influence on the accuracy, local detail 
and smoothness of DEM. According to the six interpolation methods, such as the inverse distance weighted interpolation, kriging interpolation, minimum curvature interpolation and polynomial interpolation, the DEM was constructed and evaluated by the six methods. The results shown that the interpolation accuracy of the flat terrain, the small slope is significantly higher than that of the complex and steep terrain, and compared all kinds of interpolation methods, kriging interpolation method can achieve effective and high-precision interpolation in both the low-slope and high-slope areas of the ice sheet, and the undulating terrain has less influence on the algorithm(Yang Y.D. et al.,2013). Therefore, this paper chooses Kriging interpolation to establish the Antarctic ice sheet gridization DEM.

Based on the 8-cycle altimetry data, the Kriging interpolation was used to establish the Antarctic ice sheet gridding DEM sequence after local roughing rejection and no data zone boundary control, as shown in Figure 1. It can be seen from the figure that the elevation demarcation is very obvious. There have been no major changes in the trend over the years. The average elevation of the entire Antarctic ice sheet is relatively high, and most of the areas in the Antarctic ice sheet are above $2500 \mathrm{~m}$. The elevation changes of the inland ice sheet in the Antarctic are relatively slow, the terrain is relatively flat, and the surface elevation changes in the coastal ice cap marginal area is faster and the terrain is steeper. The average elevation of the ice sheet surface in the Antarctic region is higher than that of the southwest polar ice sheet. The surface of the ice sheet in the southwest pole is undulating, and this is because the ice sheet in the southwest pole is mainly composed of a low-lying coastal ocean ice shelf and a mountainous Antarctic peninsula. The elevation of the surface in the Antarctic ice sheet rises rapidly within a few hundred kilometers of the coast, and the surface of the inland area is relatively flat with an elevation of up to 4000 meters.
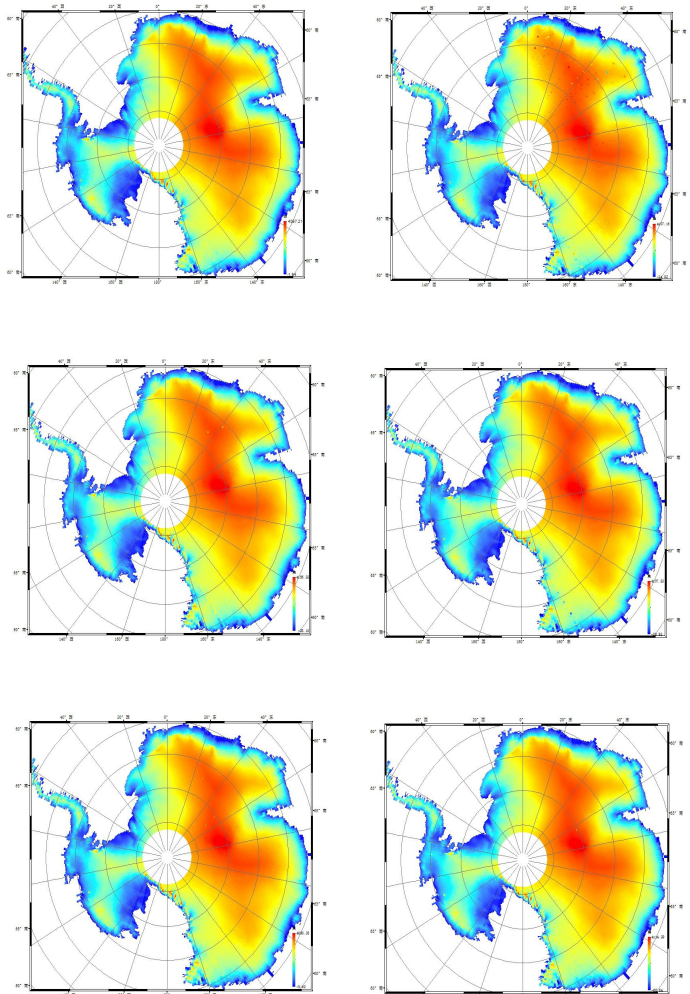
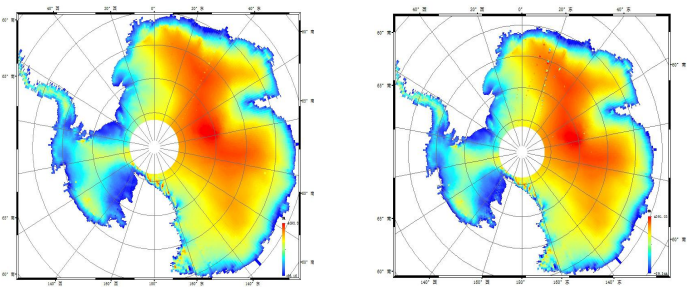

Figure 1. DEM over the cycle in Antarctica

The latitude-weighted elevation can be obtained by using the elevation data of each cycle, and then the general trend of the Antarctic ice sheet elevation variation can be seen roughly, the results are shown in Figure 2. It can be seen from the figure that the elevation of the Antarctic ice sheet shows a declining trend.Since the data in the first period is 6 months, which is slightly different from that of other cycles.From the second cycle, the elevation of the Antarctic ice sheet began to gradually decrease. From the third to the sixth cycle, the elevation change of the Antarctic ice sheet was relatively stable, and the elevations of the ice caps in the two most recent cycles decreased rapidly, showing an accelerated ablation trend.

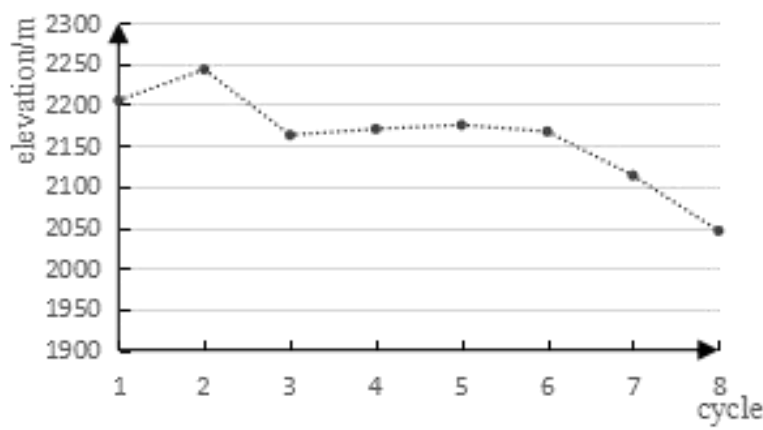

Figure 1. DEM over the cycle in Antarctica

The DEM with the relatively large time span between the 8th cycle and the 1st cycle is the difference. The obtained result is shown in Figure. 2. It can be seen that there is less change in the elevation of the Antarctic as a whole. In the southwest pole, due to the influence of the undulating terrain, the elevation changes in the region are relatively large, and there is a clear trend of melting in the fringe areas of the southeast pole and the central region where the terrain is relatively high.

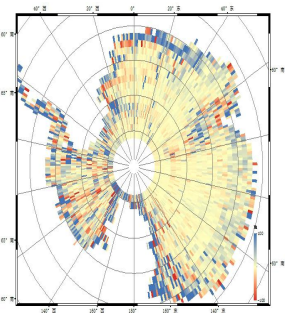

Figure 2. Difference in cycle 8 and cycle 1

\section{CONCLUSION}

The change in the Antarctic ice sheet has an important impact on the global average sea level and climate change. The Antarctic ice sheet DEM was constructed by usingthe altimetry 
data of the Cryosat-2 satellites for eight cycles from 2010 to 2017 and the Kriging interpolation method in this paper, and then elevation changes of the Antarctic ice sheet were obtained.Analysis of the elevation changes of Antarctic ice sheet:It was shown an accelerated ablation trend in the Antarctic ice sheet, and the elevation of the southeast pole is small, there is a clear trend of melting in the fringe areas of the southeast pole and the central region where the terrain is relatively high.And the elevation changes in the southwest pole are relatively large, the specific reasons for its change need to be further studied.

\section{ACKNOWLEDGEMENTS}

This research has been supported by the National Key R\&D Program of China (2016YFC1401800), the Fundamental Research Funds for the Central Universities (17CX02071), NSFC (61571009), and National Programme on Global Change and Air-Sea Interaction(GASI-02-PAC-YGST2-04, GASI-02IND-YGST2-04, GASI-02-SCS-YGST2-04).

\section{REFERENCES}

Bamber J.L., Aspinall W.P., 2013. An expert judgement assessment of future sea level rise from the ice sheets, Nature Climate Change, 3(4), pp. 424-427.

Brenner A.C., Di Marzio J.P., Zwally H.J.,2007. Precision and accuracy of satellite radar and laser altimeter data over the continental ice sheets, Geoscience and Remote Sensing, IEEE Transactions on, 45(2), pp. 321-331.

Davis C.H., Segura D.M.,2001. An algorithm for time series analysis of ice sheet surface elevations from satellite altimetry, Geoscience and Remote Sensing, IEEE Transactions on, 39(1), pp.202-206.

Pfeffer W.T., Harper J.T., O'Neel S., 2008. Kinematic constraints on glacier contributions to 21 st-century sea-level rise, Science, 321(5894), pp. 1340-1343.

Pritchard H.D., Arthern R.J., Vaughan D.G., et al., 2009, Extensive dynamic thinning on the margins of the Greenland and Antarctic ice sheets, Nature, 461(7266), pp.971-975.

Slobbe D.C., Ditmar P., Lindenbergh R.C., 2009. Estimating the rates of mass change, ice volume change and snow volume change in Greenland from ICESat and GRACE data, Geophysical Journal International, 176(1), pp. 95-106.

Slobbe D.C., Lindenbergh R.C., Ditmar P.,2008. Estimation of volume change rates of Greenland's ice sheet from ICESat data using overlapping footprints, Remote Sensing of Environment, 112(12), pp.4204-4213.

Yang Y.D., Xiong Y.Q., Wang Z.M., et al., 2013. Comparison of interpolation methods in constructing antarctic ice sheet DEM, Journal of Geodesy and Geodynamics, 33(5), pp.581-593. 